\title{
Multifaceted interventions to decrease mortality in patients with severe sepsis/septic shock - A quality improvement project
}

Brittany Siontis, Jennifer Elmer, Richard Dannielson, Catherine Brown, John Park, Salim Surani, Kannan Ramar

Despite knowledge that EGDT improves outcomes in septic patients, staff education on EGDT and compliance with the CPOE order set has been variable. Based on results of a resident survey to identify barriers to decrease severe sepsis/septic shock mortality in the medical intensive care unit (MICU), multifaceted interventions such as educational interventions to improve awareness to the importance of early goal-directed therapy (EGDT), and the use of the Computerized Physician Order Entry (CPOE) order set, were implemented in July 2013. CPOE order set was established to improve compliance with the EGDT resuscitation bundle elements. Orders were reviewed and compared for patients admitted to the MICU with severe sepsis/septic shock in July and August 2013 (controls) and 2014 (following the intervention). Similarly, educational slide sets were used as interventions for residents before the start of their ICU rotations in July and August 2013. While CPOE order set compliance did not significantly improve ( $78 \%$ vs $76 \%, p=0.74$ ), overall EGDT adherence improved from $43 \%$ to $68 \%(p=0.0295)$. Although there was a trend toward improved mortality, this did not reach statistical significance. This study shows that education interventions can be used to increase awareness of severe sepsis/septic shock and improve overall EGDT adherence. 


\section{Multifaceted interventions to decrease mortality in patients with severe sepsis/septic shock - A Quality Improvement Project}

6 ABSTRACT

7 Despite knowledge that early goal directed therapy (EGDT) improves outcomes in septic

8 patients, staff education on EGDT and compliance with the Computerized Physician Order Entry

9 (CPOE) order set that lists the components of early aggressive management with the resuscitation bundle elements, have been variable. Based on results of a resident survey to

11 identify barriers to decrease severe sepsis/septic shock mortality in the medical intensive care unit (MICU), multifaceted interventions such as educational interventions to improve awareness to the importance of EGDT, and the use of the CPOE order set, were implemented in July 2013. CPOE orders were reviewed and compared for patients admitted to the MICU with severe sepsis/septic shock in July and August 2013 (controls) and 2014 (following the intervention). Similarly, educational slide sets were used as interventions for residents before the start of their ICU rotations in July and August 2013. While CPOE order set compliance did not significantly improve ( $78 \%$ vs $76 \%, p=0.74)$, overall adherence to the resuscitation bundle elements improved from $43 \%$ to $68 \%$ ( $p=0.0295)$. This study shows that education interventions can be used to increase awareness of severe sepsis/septic shock and improve overall adherence to the resuscitation bundle elements. 


\section{Brittany Siontis MD}

25 Department of Internal Medicine

26 Mayo Clinic, 200 1st St. SW Rochester, Minnesota 55902

28 Jennifer EImer, RN

29 Department of Pulmonary \& Critical Care Medicine

30 Mayo Clinic, 200 1st St. SW Rochester, Minnesota 55902

32 Richard Danielson, $\mathbf{R N}$

Department of Pulmonary \& Critical Care Medicine

Mayo Clinic, 200 1st St. SW Rochester, Minnesota 55902

\section{Catherine Brown, RN}

Department of Pulmonary \& Critical Care Medicine

Mayo Clinic, 200 1st St. SW Rochester, Minnesota 55902 
John Park, MD

41 Department of Pulmonary \& Critical Care Medicine

42 Mayo Clinic, 200 1st St. SW Rochester, Minnesota 55902

43

\section{Salim Surani, MD, MPH, FACP, FCCP, FAASM}

45 Associate Professor, Texas A\&M University

Division of Pulmonary, Critical Care \& Sleep Medicine

47 Corpus Christi, Texas 78404

\section{Kannan Ramar MD, MBBS}

Associate Professor, Mayo Clinic

51

Division of Pulmonary and Critical Care

Mayo Clinic, 200 1st St. SW Rochester, Minnesota 55902

53

54

55

56 Corresponding Author: 


\section{Kannan Ramar}

58 Associate Professor of Medicine

59 Division of Pulmonary and Critical Care Medicine

$602001^{\text {st }}$ street SW, Rochester, MN 55901

61 Ph: 507-293-1031

62 Fax: 507-266-7772

63

64 Author Contact information:

65 Dykstra.brittany@mayo.edu; Elmer.jennifer@mayo.edu; Danielson.richard@mayo.edu;

66 Bowron.catherine@mayo.edu; Park.john@mayo.edu; srsurani@hotmail.com;

67 Ramar.kannan@mayo.edu

68

69

70 Conflict of interest - NONE

71

72

73

74

75

76

77

78

PeerJ reviewing PDF | (2015:07:5703:2:0:NEW 12 Sep 2015) 


\section{INTRODUCTION}

Aggressive and timely management of severe sepsis/septic shock is essential particularly with the increasing incidence (over one million cases projected in 2020(Angus et al. 2001)), costs (\$16.7 billion annually(Angus et al. 2001)), and burden of managing the morbidity and mortality. Rivers et al. showed the benefit of early goal-directed therapy (EGDT), with a decrease in overall mortality (46.9\% vs. $30.5 \%$ ) and length of hospital stay (18.4 vs. 14.6 days)(Rivers et al. 2001). The recent ARISE and ProCESS trials again confirm the importance of early aggressive management of patients with severe sepsis and septic shock (Investigators et al. 2014; Mouncey et al. 2015; Pro et al. 2014). However the role of all components of EGDT elements have been questioned. Despite multiple educational interventions from international societies and recommendations by the Surviving Sepsis Campaign (Dellinger et al. 2004; Dellinger et al. 2013) to institute resuscitation bundle elements in the management of severe sepsis/septic shock, all-or-none compliance with these bundle elements remain poor and the early recognition of sepsis remains a challenge (Djurkovic et al. 2010).

Various quality improvement interventions showed significant improvement in the all-or-none compliance with the resuscitation bundle elements and even more importantly, an improvement in mortality(Schramm et al. 2011). Schramm et al. implemented weekly feedback to care teams regarding their compliance in addition to starting a sepsis response team. Similarly, Coba et al. showed that monitoring the implementation of the resuscitation bundle elements by a continuous quality initiative, resulted in improvements in compliance and mortality(Coba et al. 2011). 
101 Resident physicians play a significant role in the management of patients with severe

102 sepsis/septic shock in our medical intensive care unit (MICU). Though our overall compliance

103 with the resuscitation bundle elements in our MICU ranges from $<50 \%$ to $80 \%$, it could be

104 consistently better. Resident physicians do not routinely receive data on the importance and

105 elements of aggressive early resuscitation in patients with severe sepsis/septic shock. Also, a

106 severe sepsis-specific Computerized Physician Order Entry (CPOE) that encompasses all of the

107 resuscitation bundle elements is available to assist the physicians to comply with these elements

108 (Table 1). The purpose of this quality improvement (QI) project was to identify barriers among

109 resident physicians to comply with the resuscitation bundle elements, identify and implement

110 interventions to improve compliance, and thereby reduce hospital/ICU LOS and 30 days

111 mortality.

\section{METHODS}

\section{Settings and Participants}

114 This QI project was conducted in the 24-bed MICU at Saint Mary's hospital, Rochester. Given

115 the QI nature of the project, a waiver from the Institutional Review Board was obtained. All

116 Internal Medicine (IM) residents were contacted via email giving a brief description of the QI

117 problem statement and an attached survey. The QI problem statement to the residents stated the

118 following: To decrease mortality of severe sepsis/septic shock to $10 \%$ in ICU patients by

119 increasing compliance with early aggressive management of these patients using the

120 resuscitation bundle elements by the use of the CPOE order set between 2013 and 2014 by the

121 Internal Medicine residents. Their participation in the survey was voluntary.

\section{Intervention and Comparison}


123 CPOE is the only way to place orders at our institution. The components of the CPOE order set

124 for severe sepsis/septic shock are listed in table 2. All IM resident physicians rotating through the

125 MICU during the phase of the QI project were surveyed to identify barriers to the use of CPOE

126 severe sepsis order set (Table 3). Residents rotating through the MICU change at the beginning

127 of every month with the number of residents rotating in MICU each month being the same. After

128 identifying the barriers to successful compliance from the pre-intervention survey with the CPOE

129 order set and resuscitation bundle elements, the week prior to starting the rotation, all residents

130 were provided and educated with an education slide set that detailed the importance of early

131 aggressive resuscitation of patients with severe sepsis/septic shock, and in using CPOE order sets

132 to achieve compliance with the resuscitation bundle elements. The rationale for choosing

133 education interventions along with feedback was based on the pre-survey results (in result

134 section) and discussion among the team members using the priority grid matrix to identify

135 interventions with high impact with low effort. The education interventions along with feedback

136 tools were identified to be low effort with medium impact with minimal cost to implement.

137 Compliance with resuscitation bundle elements was the major interested outcome. This slide set

138 provided step-by-step instructions on how to access the order set. Pocket cards with criteria for

139 using the order set were provided as an educational intervention, along with information

140 regarding the resuscitation bundle element components were provided to every resident rotating

141 through the ICU during the intervention period. Elements include time to antibiotics, obtaining

142 cultures before antibiotic administration, lactate measurement, appropriate and timely volume

143 resuscitation, inotrope and transfusion as appropriate (Table 1). Pocket cards also included the

144 definition of the systemic inflammatory response syndrome (SIRS), sepsis, severe sepsis and

145 septic shock to help residents identify those in need of early aggressive management of severe 
146 sepsis/septic shock. These cards were enlarged and placed on the roaming computers used

147 during rounds and MICU admissions by each resident. Finally, residents were given a bi-

148 monthly feedback sessions, compared to the pre-intervention once-monthly feedback sessions

149 regarding their compliance with meeting CPOE order set and resuscitation bundle elements. At

150 these sessions, residents were again reminded on the importance of early aggressive management

151 of severe sepsis/septic shock and compliance with the resuscitation bundle elements, along with

152 the use of the CPOE order set for all patients admitted with severe sepsis/septic shock. The

153 compliance was checked by the physician data entry in the computerized system. Additionally,

154 residents were given compliance data and feedback on the resuscitation bundle elements for

155 patients admitted during their service time who met criteria for severe sepsis/septic shock in

156 order to identify situations in which the order set should have been used.

157 The intervention was evaluated with a pre-post- test study design. To assess baseline compliance,

158 patients admitted to the MICU with severe sepsis/septic shock in July and August 2012 were

159 identified. All IM residents rotating through the MICU were administered the initial survey

160 within one week of starting their ICU rotation. Similarly, the post survey administration

161 happened within 1 week of the IM residents starting their ICU rotation following the

162 interventions. The number of IM residents rotating through each month remained the same.

163 Patients qualified as having severe sepsis/septic shock if systolic blood pressure remained $<90$

$164 \mathrm{mmHg}$ despite adequate fluid resuscitation, lactate $>4 \mathrm{mmol} / \mathrm{L}$, or organ dysfunction/failure

165 ensued due to hypoperfusion attributable to sepsis. Overall compliance with CPOE order set and

166 the resuscitation bundle elements were determined by reviewing orders placed for patients

167 admitted to the MICU with severe sepsis/septic shock. The interventions were implemented on

168 July 1, 2013. Compliance with CPOE order set use and resuscitation bundle elements for patients 
169 admitted in July and August 2013 were assessed for comparison. Following the intervention

170 period, the survey was re-administered to the IM residents who had rotated through the MICU,

171 with additional questions addressing which interventions were beneficial in improving

172 compliance.

\section{Outcomes and Data Collection}

174 The MICU sepsis group keeps a database of patients admitted with severe sepsis/septic shock.

175 Patients with severe sepsis were initially identified by screening criteria using the sepsis alert

176 software in our MICU. Our quality coach nurses subsequently screened these patients to confirm

177 the diagnosis of severe sepsis/septic shock before the data were manually entered in the MICU

178 database. The team leaders performed periodic checks to check the validity. This database was

179 used to identify patients in our timeframe of interest and to assess compliance. Once identified,

180 orders placed for each patient were reviewed. Use of the CPOE order set was recorded, as well

181 as whether $100 \%$ of the resuscitation bundle elements were met. Our experienced and ICU

182 trained nurses were the quality coaches who collected all the relevant outcome data. The two

183 nurses who were the quality coaches underwent rigorous training in data collection and analysis.

184 They had a trial run of collecting and analyzing data in the QI project that was subsequently

185 supervised by a quality expert in ICU for reliability and validity before they started this project.

186 The two nurses conducted and collected the pre and post intervention data. Though the quality

187 coach nurses were not blinded, the consistency of collection of data were reliable and valid as

188 periodic checks were performed independently by the MD quality expert. Demographic data,

189 outcomes including MICU and hospital length of stay, Acute Physiology and Chronic Health

190 Evaluation II (APACHE II) score, Sequential Organ Failure Assessment (SOFA) score and

191 mortality were also collected by our quality coaches. 
192

193

194

195

\section{Statistical Analysis}

Statistical differences in patient demographics, CPOE compliance, resuscitation bundle elements compliance and 30-day mortality were compared between pre- and post-intervention groups using a chi square model. Statistical differences between median hospital and ICU length of stay (LOS) were compared using Mann-Whitney test using R Statistical Software (Foundation for statistical computing, Vienna, Austria).

\section{RESULTS}

\section{Survey Results}

First and third year residents rotated in our MICU. In the pre-intervention period, 56 of 170 IM residents who had rotated in our MICU during the QI project, participated in the survey with 31 $(55 \%)$ of respondents being first year residents. In our MICU, it is the first year residents who are primarily responsible for order entry. The majority of residents $(89 \%)$ were familiar with the order sets, however only $67 \%$ felt knowledgeable about when to use the order set. Additionally, $63 \%$ of residents identified at least one situation in which they later realized the order set applied to their patient. Uncertainty as to whether the CPOE order set applied to a particular patient with severe sepsis/septic shock ( $45 \%$ of respondents) was the largest barrier to order set compliance according to survey results from IM residents (Figure 1A). They identified reminders from staff as the most likely factor to promote order set use (Figure 1B).

In the post-intervention period, 44 of 170 IM residents who rotated in our MICU participated in the survey with $41 \%$ of respondents being first year residents. The greatest barrier to order set 
213 use remained uncertainty about whether it applied to their patient (36\% of respondents). Again,

214 reminders from staff were considered to be the most likely factor to improve compliance. The

215 post-intervention survey contained questions directed at the interventions themselves.

216 Educational interventions (23\%) and bimonthly feedback (23\%) were found to be most useful,

217 while $25 \%$ of residents felt all of the interventions were equally helpful in improving

218 compliance. Thirty percent of residents felt the interventions increased knowledge and awareness

219 of severe sepsis/septic shock, while $11 \%$ found that the interventions increased awareness about

220 the resuscitation bundle elements and thus increased CPOE order set compliance. Twenty seven

221 percent of residents found increased awareness of both severe sepsis/septic shock and the

222 resuscitation bundle elements from these interventions. Finally, $66 \%$ of residents reported using

223 the CPOE order set always or most of the time, while only $9 \%$ reported rarely using the order set.

224 There were 51 patients admitted to the MICU for severe sepsis/septic shock in the pre-

225 intervention period and 41 patients in the post-intervention period. Baseline demographics are

226 shown in Table 4. There were no significant differences in age or BMI. The pre-treatment group

227 had a higher percentage of males (59\%) while the post-intervention period had more female

228 admissions (56\%); however these were not statistically different (Table 4).

229 Pre-intervention CPOE compliance was $78 \%$ while post-intervention compliance was $76 \%$

$230(\mathrm{p}=0.74)$. Compliance with meeting $100 \%$ of the resuscitation bundle elements was $43 \%$ in the

231 pre-intervention and improved significantly to $68 \%$ in the post-intervention period $(\mathrm{p}=0.0295)$.

232 The median hospital LOS pre-intervention was 7.43 (range 3.85-16.09) days and decreased to

2335.54 (range 3.31-9.62) days post-intervention ( $\mathrm{p}=0.11$, Table 4). The median MICU LOS was

$2342.03(1.34-3.83)$ day pre-intervention and decreased to $1.55(0.92-2.96)$ days post intervention 
$235(\mathrm{p}=0.085)$. The 30 -day mortality was $25 \%$ in the pre-intervention period and $12 \%$ in the post-

236 intervention period $(\mathrm{p}=0.14)$ (Table 5).

\section{DISCUSSION}

238 Our QI initiative that used multifaceted educational and feedback interventions based on the

239 identified barriers, successfully improved the overall compliance with the resuscitation bundle

240 elements (43 to $68 \%, \mathrm{p}=0.0295$ ), decreased the ICU and hospital length of stay. These findings

241 were reached despite a lack of significant improvement in the CPOE order set compliance,

242 emphasizing the important of education, feedback and overall increasing the awareness of early

243 aggressive management of patients with severe sepsis and septic shock among resident

244 physicians.

245 The primary barrier identified though the resident survey was the lack of understanding on when

246 to use the CPOE order set. We suspect that this lack of understanding stemmed from a deficiency

247 of knowledge regarding the definition of severe sepsis/septic shock and what parameters are used

248 to define and identify these patients. The education intervention not only provided information

249 regarding early aggressive management with the use of resuscitation bundle elements and its

250 importance, but also definitions from SIRS to severe sepsis/septic shock. Post-intervention

251 surveys confirmed the increased awareness of when to use the order set.

252 Several studies have investigated educational interventions to improve compliance with the

253 resuscitation bundle elements as outline by the surviving sepsis campaign guidelines (Levy et al.

254 2010; Nguyen et al. 2007; Schramm et al. 2011). A prospective study of severe sepsis in 54 ICUs

255 in Spain noted an improvement of overall compliance with the sepsis resuscitation bundle from

$2565.3 \%$ to $10 \%$ based on educational interventions(Ferrer et al. 2008). Our study also shows that 
257 educational interventions alone can improve compliance with meeting the resuscitation bundle

258 elements. In addition to educational interventions, this quality improvement project also

259 provided bi-monthly feedback to residents on their overall compliance. The study in Spain

260 focused on all-or-none compliance, while our study focused on order set compliance. The

261 educational interventions in our study were similar to those in Spain, which provided pocket

262 cards, posters and educational slides with definitions of severe sepsis and septic shock,

263 appropriate management, and periodic feedback on performance(Ferrer et al. 2008). Their

264 intervention also included providing educational materials to emergency department and surgical

265 physicians.

266 Nguyen et al(Nguyen et al. 2007) showed increased compliance with the resuscitation bundle

267 elements from $0 \%$ to $51.2 \%$ using educational interventions in addition to feedback on a

268 quarterly basis. Our study differs in that feedback was provided on a bi-monthly basis. Their

269 study also differed in that interventions were initiated in the Emergency Department, while our

270 interventions were in the MICU. With quarterly feedback to nurses and physicians, they saw an

271 increase in sepsis resuscitation bundle elements compliance from zero to $51.2 \%$ at the end of two

272 years. They noted no change in ED LOS or hospital LOS between patients with and without

273 bundle elements completed.

274 Though, all-or-none compliance improved significantly post intervention in our study, the

275 compliance with the use of the CPOE order set did not improve. There are various reasons to

276 explain this discrepancy. It is likely that some of the resuscitation bundle elements were being

277 done prior to the patient's admission to the MICU, particularly in the Emergency department

278 (ED). For example, many patients have central lines placed and initial laboratory evaluations 
279 done in the ED. In those situations, some find it easier to place individual orders for elements

280 still needed to best coordinate timing of repeat labs rather than going through the entire order set.

281 Additionally, some elements of the CPOE order set may be omitted if the resident did not feel

282 that particular element was necessary. This was particularly true for patients who did not have a

283 central access for $\mathrm{ScvO} 2$ monitoring. The unchecking of certain elements of the CPOE order set

284 would have then resulted in non-compliance with the resuscitation bundle elements. Finally,

285 practitioners often have their own method of approaching patient management. Some prefer to

286 think about each element of the resuscitation bundle elements individually rather than ordering

287 them as a whole. This would be unlikely to change with our interventions, and therefore still

288 contributes to reduced compliance.

289 A study by Rubenfeld in 2004 categorized reasons for the discordance between guidelines and

290 practice into three groups: knowledge barriers, attitude barriers and behavioral

291 barriers(Rubenfeld 2004). While our intervention was knowledge focused, perhaps the most

292 difficult to address, and likely the cause for ongoing imperfect compliance, is attitude barriers.

293 We can hope that through continued education, these attitudes will change.

294 Rivers et al. found mortality of the control group to be $45.6 \%$ compared to $30.5 \%$ in the EGDT

295 group(Rivers et al. 2001). Additionally, a study by Lin et al. showed a mortality rate of $71.6 \%$ in

296 the control group compared with 53.7\% in the EGDT group(Lin et al. 2006). Compared with

297 these trials, our baseline mortality of $25 \%$ is lower, and more in line with the outcomes of recent

298 trials, which showed 18-21\% mortality(Investigators et al. 2014; Pro et al. 2014). For several

299 years, our institution has stressed the importance of identifying patients with severe sepsis/septic

300 shock and meeting EGDT standards. Several QI projects, such as that by Schramm et 
$301 \mathrm{al}$ (Schramm et al. 2011), have been aimed at this mission, contributing to our low baseline

302 mortality.

303 There are several limitations to this study. This is a single-centered study with a distinct

304 organization and staffing, making generalizability difficult. Additionally, the pre- and post-

305 intervention time periods were only two months. The sample sizes of the patients that were

306 studied were small, which contributed to the lack of statistical significance in some of the

307 outcome measures.

\section{Conclusion:}

309 In conclusion, we have shown that a multifaceted intervention strategy of educational

310 intervention to our resident physicians to increase awareness of early aggressive management

311 using the resuscitation bundle elements in patients with severe sepsis and septic shock, along

312 with continued feedback on performance on these measures, resulted in significant

313 improvements in all or none compliance with resuscitation bundle elements and trended toward

314 improved mortality among severe sepsis and septic shock patients in our MICU. This method

315 and success can be applied towards improving the attitude and behavioral changes towards other

316 disease specific order sets. We plan to sustain this improvement with continued feedback along

317 with the educational intervention. 
REFERENCES

Angus DC, Linde-Zwirble WT, Lidicker J, Clermont G, Carcillo J, and Pinsky MR. 2001. Epidemiology of severe sepsis in the United States: analysis of incidence, outcome, and associated costs of care. Crit Care Med 29:1303-1310.

Coba V, Whitmill M, Mooney R, Horst HM, Brandt MM, Digiovine B, Mlynarek M, McLellan B, Boleski G, Yang J, Conway W, and Jordan J. 2011. Resuscitation bundle compliance in severe sepsis and septic shock: improves survival, is better late than never. J Intensive Care Med 26:304-313. 10.1177/0885066610392499

Dellinger RP, Carlet JM, Masur H, Gerlach H, Calandra T, Cohen J, Gea-Banacloche J, Keh D, Marshall JC, Parker MM, Ramsay G, Zimmerman JL, Vincent JL, Levy MM, and Surviving Sepsis Campaign Management Guidelines C. 2004. Surviving Sepsis Campaign guidelines for management of severe sepsis and septic shock. Crit Care Med 32:858-873.

Dellinger RP, Levy MM, Rhodes A, Annane D, Gerlach H, Opal SM, Sevransky JE, Sprung CL, Douglas IS, Jaeschke R, Osborn TM, Nunnally ME, Townsend SR, Reinhart K, Kleinpell RM, Angus DC, Deutschman CS, Machado FR, Rubenfeld GD, Webb S, Beale RJ, Vincent JL, Moreno R, and Surviving Sepsis Campaign Guidelines Committee including The Pediatric S. 2013. Surviving Sepsis Campaign: international guidelines for management of severe sepsis and septic shock, 2012. Intensive Care Med 39:165-228. 10.1007/s00134-012-2769-8

Djurkovic S, Baracaldo JC, Guerra JA, Sartorius J, and Haupt MT. 2010. A survey of clinicians addressing the approach to the management of severe sepsis and septic shock in the United States. $J$ Crit Care 25:658 e651-656. 10.1016/j.jcrc.2010.04.005

Ferrer R, Artigas A, Levy MM, Blanco J, Gonzalez-Diaz G, Garnacho-Montero J, Ibanez J, Palencia E, Quintana M, de la Torre-Prados MV, and Edusepsis Study G. 2008. Improvement in process of care and outcome after a multicenter severe sepsis educational program in Spain. Jama 299:2294-2303. 10.1001/jama.299.19.2294

Investigators A, Group ACT, Peake SL, Delaney A, Bailey M, Bellomo R, Cameron PA, Cooper DJ, Higgins AM, Holdgate A, Howe BD, Webb SA, and Williams P. 2014. Goal-directed resuscitation for patients with early septic shock. N Engl J Med 371:1496-1506. 10.1056/NEJMoa1404380

Levy MM, Dellinger RP, Townsend SR, Linde-Zwirble WT, Marshall JC, Bion J, Schorr C, Artigas A, Ramsay G, Beale R, Parker MM, Gerlach H, Reinhart K, Silva E, Harvey M, Regan S, and Angus DC. 2010. The Surviving Sepsis Campaign: results of an international guideline-based performance improvement program targeting severe sepsis. Intensive Care Med 36:222-231. 10.1007/s00134009-1738-3

Lin SM, Huang CD, Lin HC, Liu CY, Wang CH, and Kuo HP. 2006. A modified goal-directed protocol improves clinical outcomes in intensive care unit patients with septic shock: a randomized controlled trial. Shock 26:551-557. 10.1097/01.shk.0000232271.09440.8f

Mouncey PR, Osborn TM, Power GS, Harrison DA, Sadique MZ, Grieve RD, Jahan R, Harvey SE, Bell D, Bion JF, Coats TJ, Singer M, Young JD, Rowan KM, and Pro MTI. 2015. Trial of early, goal-directed resuscitation for septic shock. N Engl J Med 372:1301-1311. 10.1056/NEJMoa1500896

Nguyen HB, Corbett SW, Steele R, Banta J, Clark RT, Hayes SR, Edwards J, Cho TW, and Wittlake WA. 2007. Implementation of a bundle of quality indicators for the early management of severe sepsis and septic shock is associated with decreased mortality. Crit Care Med 35:1105-1112. 10.1097/01.CCM.0000259463.33848.3D 
Pro Cl, Yealy DM, Kellum JA, Huang DT, Barnato AE, Weissfeld LA, Pike F, Terndrup T, Wang HE, Hou PC, LoVecchio F, Filbin MR, Shapiro NI, and Angus DC. 2014. A randomized trial of protocol-based care for early septic shock. N Engl J Med 370:1683-1693. 10.1056/NEJMoa1401602

Rivers E, Nguyen B, Havstad S, Ressler J, Muzzin A, Knoblich B, Peterson E, Tomlanovich M, and Early Goal-Directed Therapy Collaborative G. 2001. Early goal-directed therapy in the treatment of severe sepsis and septic shock. N Engl J Med 345:1368-1377. 10.1056/NEJMoa010307

Rubenfeld GD. 2004. Translating clinical research into clinical practice in the intensive care unit: the central role of respiratory care. Respir Care 49:837-843.

Schramm GE, Kashyap R, Mullon JJ, Gajic O, and Afessa B. 2011. Septic shock: a multidisciplinary response team and weekly feedback to clinicians improve the process of care and mortality. Crit Care Med 39:252-258. 10.1097/CCM.0b013e3181ffde08 
1

Figure $1(A \& B)$ 


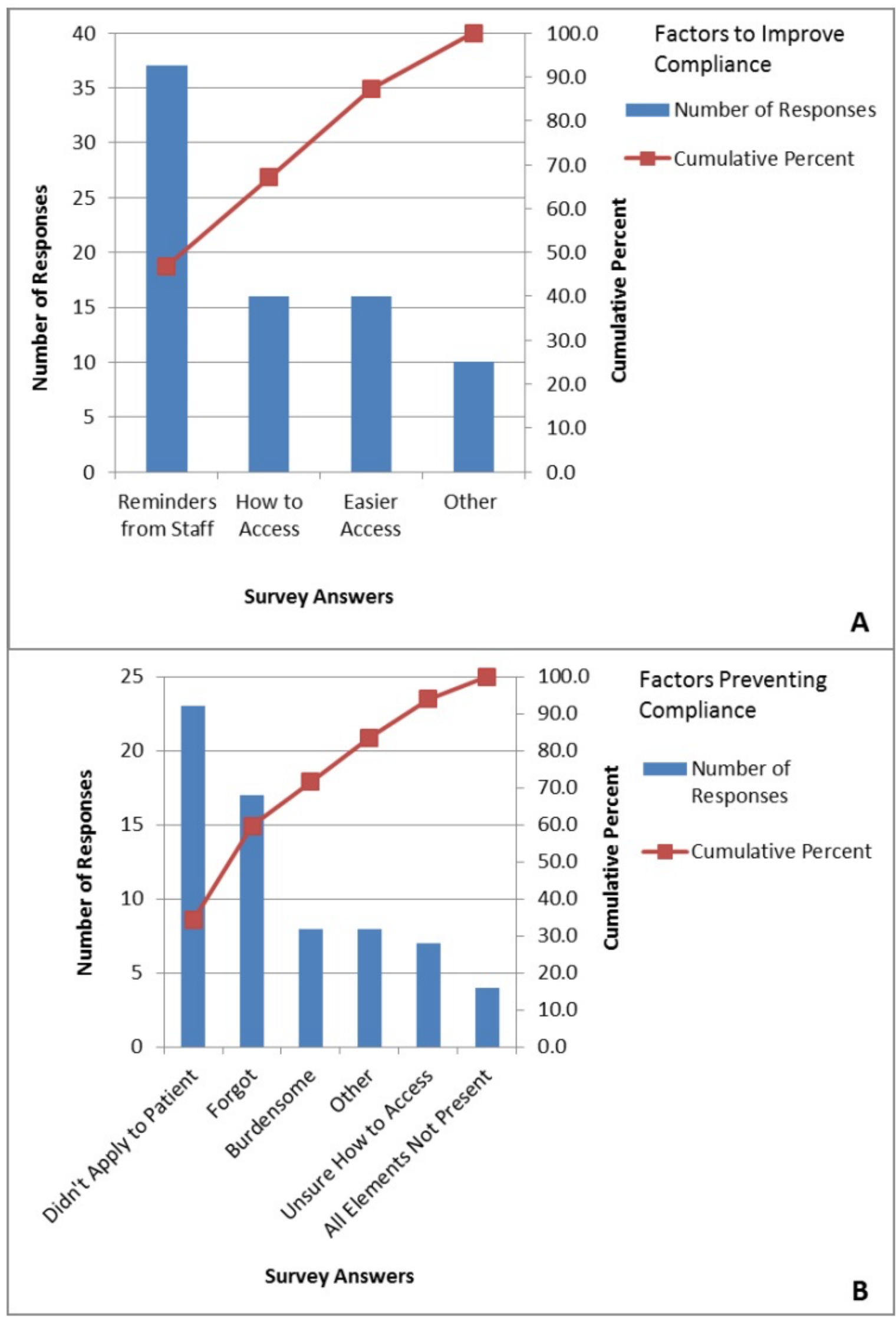




\section{Table 1 (on next page)}

Table 1

Quality parameters in the elderly resuscitation bundle 


\begin{tabular}{|c|c|}
\hline 1 & Lactate: Measured before or within $1 \mathrm{~h}$ after blood culture \\
\hline 2 & Blood culture: Drawn before antibiotics \\
\hline 3 & Antibiotic: Administered within $1 \mathrm{~h}$ of severe sepsis onset \\
\hline 4 & $\begin{array}{l}\text { Fluid: Fluid given until one of the following } \\
\text { a. } \mathrm{CVP} \geq 8 \text { (on } \mathrm{MV} 12 \text { ) } \mathrm{mm} \mathrm{Hg} \\
\text { b. } \mathrm{MAP} \geq 65 \mathrm{~mm} \mathrm{Hg} \text { and lactate }<2.5 \mathrm{mmol} / \mathrm{L} \text { and } \mathrm{UO}>0.5 \mathrm{~mL} / \mathrm{kg} \text {.h } \\
\text { c. } 12 \mathrm{~L} \text { of crystalloid equivalent }\end{array}$ \\
\hline 5 & $\begin{array}{l}\text { Vasopressor: Administered for } 1 \text { of the following } \\
\text { a. MAP }<65 \mathrm{~mm} \mathrm{Hg} \text { despite fluid challenge } \\
\text { b. MAP }<50 \mathrm{~mm} \mathrm{Hg} \text { for } \geq 15 \mathrm{~min}\end{array}$ \\
\hline 6 & $\begin{array}{l}\mathrm{RBC} \text { : Transfused if } \mathrm{Hct}<30 \% \text { and } \mathrm{ScVO}_{2}<70 \% \text { or mixed venous } \mathrm{O} 2 \text { sat }<65 \% \text { despite fluid } \\
\text { resuscitation ( } \mathrm{RBC} \text { before adequate fluid resuscitation is inappropriate) }\end{array}$ \\
\hline 7 & $\begin{array}{l}\text { notrope: } \text { Started if } \mathrm{Hct} \geq 30 \% \text { and } \mathrm{ScVO}_{2}<70 \% \text { or mixed venous } \mathrm{O} 2 \text { sat }<65 \% \text { despite fluid } \\
\text { resuscitation (Inotrope before adequate fluid resuscitation is inappropriate }\end{array}$ \\
\hline
\end{tabular}




\section{Table 2 (on next page)}

Table 2

Components of the severe sepsis/septic shock management CPOE order set 
ALERT

- Administer appropriate parenteral antibiotic within 1 hour of sepsis recognition. The choice of antibiotics will depend on likelihood of specific infection, the patient immune status and allergies.

- Consider the following consults (if sepsis source known): • Infectious Disease. • General Surgery. • Interventional Radiology.

- Activate Sepsis Response Team (if applicable to area) or appropriate resuscitation personnel is not available

Components of the order set checked by the provider:

1. Organ Perfusion:

a. Obtain arterial blood gas every __ hour(s) for ___ hours.

b. Obtain central venous saturations (ScvO2 or SvO2) every_(1-2 hours) place as guide under line__ hour(s) for _ 6 (pre-filled)_ hours.

c. Obtain Point Of Care serum lactate STAT. (should be a pre-checked box electronically)

d. Obtain serum lactate every_(1-2 hours) place as guide under line __ hour(s) for _ 6 (pre-filled)_ hours. (should be a pre-checked box electronically)

2. Lab: Serum fasting glucose (not pre-checked).

3. Blood type and screen.

4. Vascular Access:

a. Insert central line (do not have pre-checked).

5. Antibiotics

a. (Various choices of antibiotics are listed and appropriate check boxes are present to be clicked)

6. Volume resuscitation: (At least $30 \mathrm{ml} / \mathrm{kg}$ liters of fluid of one of the following)

a. Lactated Ringers $1000 \mathrm{~mL}$ IV PRN over 15 minutes up to a maximum of $\mathrm{mL}$ until 
one of the following are achieved:

b. $0.9 \% \mathrm{NaCL} 1000 \mathrm{~mL}$ IV PRN over 15 minutes up to a maximum of $\mathrm{mL}$ or for 24 hours until one of the following is achieved:

c. Albumin $5 \% 500 \mathrm{~mL}$ IV PRN over 15 minutes up to a maximum of $\mathrm{mL}$ until one of the following is achieved:

i. To keep central venous pressure (CVP) at $12-15 \mathrm{mmHg}$ (mechanically ventilated) or 8-12 $\mathrm{mmHg}$ (not mechanically ventilated).

ii. Central Venous Pressure (CVP) $\geq 8$ (on Mechanical Ventilation $\geq 12$ ) $\mathrm{mmHg}$

iii. $\mathrm{MAP} \geq 65 \mathrm{mmHg}$ and lactate $<2.5 \mathrm{mmol} / \mathrm{L}$ and $\mathrm{UO}>0.5 \mathrm{ml} / \mathrm{kg} / \mathrm{hr}$

iv. Lack of fluid responsiveness based on dynamic or static variables assessment

7. Vasopressor infusion: Note: Recommend use only with central line, but in extreme emergency, vasopressors may be given for a brief period of time via peripheral site with constant monitoring for extravasation. Vasopressor should be administered for MAP $<65 \mathrm{mmHg}$ despite fluid challenge (30 ml/kg) (OR) MAP $<50 \mathrm{mmHg}$ for $\geq 15 \mathrm{~min}$

a. Norepinephrine infusion $0.05 \mathrm{mcg} / \mathrm{kg} / \mathrm{minute}$, titrate by $0.05 \mathrm{mcg} / \mathrm{kg} /$ minute every 5 minutes to keep MAP $\geq 6560-80 \mathrm{mmHg}$.

b. Vasopressin 0.03 units/minute, do not titrate.

c. Phenylephrine infusion $0.5 \mathrm{mcg} / \mathrm{kg} /$ minute, titrate by $0.1 \mathrm{mcg} / \mathrm{kg} / \mathrm{minute}$ every 5 minutes to keep MAP $\geq 6560-80 \mathrm{mmHg}$.

d. Epinephrine infusion $0.05 \mathrm{mcg} / \mathrm{kg} /$ minute, titrate by $0.05 \mathrm{mcg} / \mathrm{kg} / \mathrm{minute}$ every 5 minutes to keep MAP $\geq 6560-80 \mathrm{mmHg}$.

8. Target ScVO2 $\geq 70$ (or SvO2 less than $65 \%$ ) and downward trending Lactate towards normal values by considering (one or more of the following):

a. If ScvO2 less than $70 \%$ or SvO2 less than $65 \%$ (decreased oxygen delivery in spite of 
adequate volume replacement and preload):

i. Dobutamine infusion $5 \mathrm{mcg} / \mathrm{kg} /$ minute titrate by $2.5 \mathrm{mcg} / \mathrm{kg} /$ minute every 10 minutes up to a maximum of $15 \mathrm{mcg} / \mathrm{kg} /$ minute to keep ScvO2 greater than $70 \%$ or SvO2 greater than $65 \%$.

ii. Milrinone $0.375 \mathrm{mcg} / \mathrm{kg} / \mathrm{minute}$ titrate up to a maximum of 0.75 $\mathrm{mcg} / \mathrm{kg} / \mathrm{min}$ te to keep ScvO2 greater than $70 \%$ or SvO2 greater than $65 \%$.

b. If anemia present, consider transfusing packed red blood cells for a hemoglobin level less than $710 \mathrm{mg} / \mathrm{dL}$.

1 


\section{Table 3(on next page)}

Table 3

Pre- and post intervention survey questions 


\begin{tabular}{|c|c|}
\hline Question & Answer Choices \\
\hline Indicate year of training & $\begin{array}{l}\text { PGY-1 } \\
\text { PGY-2 } \\
\text { PGY-3 }\end{array}$ \\
\hline Number of months spent in MICU & $\begin{array}{l}0 \text { months } \\
1 \text { month } \\
2 \text { months } \\
>2 \text { months }\end{array}$ \\
\hline $\begin{array}{l}\text { Are you familiar with the severe sepsis order set } \\
\text { in MICS? }\end{array}$ & $\begin{array}{l}\text { Yes } \\
\text { No }\end{array}$ \\
\hline $\begin{array}{l}\text { Were you knowledgeable/aware of when to and } \\
\text { when not to use the order set? }\end{array}$ & $\begin{array}{l}\text { Yes } \\
\text { No }\end{array}$ \\
\hline $\begin{array}{l}\text { Did you have occasions when you later realized } \\
\text { you should have instituted the severe sepsis } \\
\text { order set? }\end{array}$ & $\begin{array}{l}\text { Yes } \\
\text { No }\end{array}$ \\
\hline $\begin{array}{l}\text { What factors prevented you from using the } \\
\text { severe sepsis order set? (please select all that } \\
\text { apply) }\end{array}$ & $\begin{array}{l}\text { Forgot } \\
\text { Didn't think it applied } \\
\text { Burdensome to use order set } \\
\text { Did not know how to access order set } \\
\text { Did not think order set had all elements needed }\end{array}$ \\
\hline $\begin{array}{l}\text { What factors are likely to promote the increased } \\
\text { use of the severe sepsis order set? (Please select } \\
\text { all that apply) }\end{array}$ & $\begin{array}{l}\text { Easier accessibility in MICS } \\
\text { Demonstration on how to access order set } \\
\text { Reminders from seniors/fellows/staff to use the } \\
\text { order set }\end{array}$ \\
\hline $\begin{array}{l}\text { * Post intervention questions only } \\
\text { Which among the below interventions has helped } \\
\text { you the most to comply with the severe sepsis } \\
\text { order set? }\end{array}$ & $\begin{array}{l}\text { Educational interventions } \\
\text { Bimonthly feedback to the team } \\
\text { Reminders posted on the computers } \\
\text { All of the above }\end{array}$ \\
\hline $\begin{array}{l}\text { * Post intervention questions only } \\
\text { How have the above interventions helped? }\end{array}$ & $\begin{array}{l}\text { Improve CPOE order set compliance } \\
\text { Increased knowledge and awareness of severe } \\
\text { sepsis/septic shock } \\
\text { Increased awareness to be compliant with the } \\
\text { resuscitation bundle elements } \\
\text { All of the above }\end{array}$ \\
\hline $\begin{array}{l}\text { * Post intervention questions only } \\
\text { While in the MICU, have you been using the } \\
\text { severe sepsis/septic shock CPOE order set? }\end{array}$ & $\begin{array}{l}\text { Always } \\
\text { Most of the time } \\
\text { Some of the time } \\
\text { Rarely }\end{array}$ \\
\hline
\end{tabular}




\section{Table 4(on next page)}

Table 4

Demographics 


\begin{tabular}{llll}
\hline & Pre-Intervention (N=51) & Post-Intervention (N=41) & P value \\
\hline $\begin{array}{l}\text { Mean Age } \\
\text { Years (SD) }\end{array}$ & $66(13.7)$ & $68(16.3)$ & 0.61 \\
$\begin{array}{l}\text { Gender } \\
\text { N (\%) }\end{array}$ & F 21 (41) & F 23 (56) & 0.09 \\
BMI & M 30 (59) & M 18 (44) \\
Mean (SD) & $30.7(9.26)$ & $29.2(6.39)$ & 0.46 \\
$\begin{array}{l}\text { APACHE } \\
\text { Mean (SD) }\end{array}$ & $85.5(26.9)$ & $78.2(29.0)$ & 0.19 \\
$\begin{array}{l}\text { SOFA } \\
\text { Mean (SD) }\end{array}$ & $7.61(4.17)$ & $7.49(4.13)$ & 0.89 \\
\hline
\end{tabular}

2 


\section{Table 5 (on next page)}

Table 5

Outcomes 


\begin{tabular}{llll}
\hline & $\begin{array}{l}\text { Pre-Intervention } \\
(\mathbf{N}=51)\end{array}$ & $\begin{array}{l}\text { Post-Intervention } \\
(\mathbf{N}=\mathbf{4 1})\end{array}$ & P value \\
\hline $\begin{array}{l}\text { Hospital LOS } \\
\text { Median (IQR) }\end{array}$ & $7.43(3.85-16.09)$ & $5.54(3.31-9.62)$ & 0.11 \\
$\begin{array}{l}\text { MICU LOS } \\
\text { Median (IQR) }\end{array}$ & $2.03(1.34-3.83)$ & $1.55(0.92-2.96)$ & 0.85 \\
$\begin{array}{l}\text { Mortality 30 day } \\
\text { N(\%) }\end{array}$ & $13(25)$ & $5(12)$ & 0.14 \\
\hline
\end{tabular}

2

3

4

5

6

7

8

9 